\title{
Gestão participativa da pesca no Brasil: levantamento das iniciativas e documentação dos processos
}

\section{Participatory Management of Fisheries in Brazil: Proposals, Projects and Process Documentation}

\author{
Cristiana Simão SEIXAS* \\ Daniela Coswig KALIKOSKI**
}

\begin{abstract}
RESUMO
Este trabalho buscou identificar as formas de arranjos institucionais relacionados à gestão participativa da pesca no Brasil, onde estes processos de gestão estão ocorrendo e como têm sido documentados. Para tanto, 97 documentos relacionados à gestão participativa da pesca foram analisados. Notamos que há diferenças regionais gritantes, com implicações para políticas pesqueiras e políticas de fomento à pesquisa sobre $\mathrm{o}$ assunto.
\end{abstract}

Palavras-chave: gestão participativa; gestão compartilhada; pesca; pesquisa; Brasil.

\begin{abstract}
This work identifies institutional arrangements concerning participatory management of fisheries in Brazil, investigating where such arrangements take place, and how they have been documented. For this purpose we analyzed 97 documents related to participatory management of fisheries. We noted that regional differences exist, and they have implications for fishery policies as well as research funding policies.
\end{abstract}

Key-words: participatory management; co-management; fisheries; research; Brazil.

\section{Introdução}

Experiências de gestão pesqueira com a participação de pescadores têm ocorrido em diversas regiões do Brasil e de formas diferentes. Entretanto, ainda não há uma sistematização das informações sobre onde estas experiências têm ocorrido, de que forma estão estruturadas (i.e., qual o tipo de arranjo institucional), e quais os avanços e desafios enfrentados pela maioria dos casos. Esta sistematização é importante tanto para compartilhar as lições já aprendidas com gestores, pescadores e pesquisadores, como para indicar as lacunas no conhecimento sobre este assunto. Nossa pesquisa busca realizar tal sistematização em dois traba-

\footnotetext{
" Bióloga. Pesquisadora do Núcleo de Estudos e Pesquisas Ambientais (NEPAM), Área de Ecologia e Conservação, Universidade Estadual de Campinas (UNICAMP).Email: csseixas@hotmail.com.

** Geógrafa. Núcleo de Estudo e Capacitação em Gestão Compartilhada e Comunitária da Pesca, Instituto de Ciências Humanas e da Informação, Universidade Federal do Rio Grande (FURG). Email: docdck@super.furg.br.
} 
lhos. O presente trabalho investiga as propostas, projetos e documentação dos processos de gestão participativa da pesca no Brasil, e um segundo trabalho (KALIKOSKI et al., no prelo) investiga os avanços e desafios para a gestão compartilhada e comunitária da pesca no Brasil.

A Gestão Participativa da Pesca pode ser entendida como o envolvimento dos usuários diretos dos recursos, isto é, os pescadores, nos processos de planejamento, implementação e monitoramento/avaliação de planos de manejo dos recursos pesqueiros. Outros atores que utilizam os mesmos espaços ou outros recursos dentro destes espaços podem e, muitas vezes, devem participar também dos processos de gestão participativa da pesca. $\mathrm{O}$ grau de envolvimento dos pescadores e demais atores na gestão da pesca pode variar bastante, desde uma mera consulta pelo governo sobre os interesses e propostas feitas pelos usuários, até o manejo totalmente comunitário - isto é, planejado, implementado e monitorado pelas comunidades sem a participação governamental (BERKES et al., 2001). Sen e Nielsen (1996) sintetizam cinco formas de arranjos institucionais que descrevem o envolvimento de usuários na gestão da pesca; são eles:

1. Gestão instrutiva: Há pouca troca de informação entre governo e usuários, e o governo apenas informa os usuários das decisões que pretende tomar.

2. Gestão consultiva: Há mecanismos para o governo consultar a opinião dos usuários, mas todas as decisões são tomadas pelo governo.

3. Gestão cooperativa ou compartilhada: As decisões são tomadas em cooperação entre governo e usuários.

4. Gestão de aconselhamento: Os usuários aconselham o governo das decisões a serem tomadas, e o governo, de maneira geral, aprova tais decisões.

5. Gestão informativa: O governo delega as tomadas de decisão aos usuários, que são responsáveis por informar o governo das decisões tomadas.

No Brasil, vários outros termos são utilizados para descrever diferentes arranjos de gestão participativa, entre eles: gestão compartilhada, cogestão, manejo comunitário, manejo participativo, manejo local, comanejo, e cogerenciamento. Não cabe aqui descrever as sutis diferenças entre tais termos; entretanto, vale ressaltar que todos estes termos passam a ideia de que os usuários dos recursos possuem algum envolvimento nos processos de gestão.

Este trabalho busca identificar as formas de arranjos institucionais relacionados à gestão participativa da pesca, onde tais processos de gestão participativa estão ocorrendo dentro do território brasileiro e como estes processos têm sido documentados. O objetivo é contribuir para o enriquecimento do conhecimento sobre a gestão participativa da pesca no Brasil a fim de subsidiar o empoderamento das comunidades de pescadores, políticas pesqueiras, e políticas de fomento à pesquisa sobre os processos de gestão participativa da pesca bem como identificar lacunas de informação.

\section{Métodos de estudo}

O estudo baseou-se em um levantamento bibliográfico sobre produção científica e artigos de divulgação relacionados à gestão participativa da pesca no Brasil. A coleta de dados foi realizada em janeiro e fevereiro de 2006 , utilizando 40 combinações de palavras-chave em português e 20 em inglês. Foram pesquisados 69 sítios e páginas da Internet, incluindo bancos de referências bibliográficas, páginas da Web de ONGs ambientalistas e de instituições governamentais estaduais e federais (Anexo I).

Um total de 97 documentos foi coletado, entre artigos científicos, artigos de divulgação, livros ou capítulos de livros, materiais para divulgação, projetos de pesquisa e/ou pesquisa-ação, relatórios técnicos, resumos de apresentações em reuniões científicas, teses/dissertações/monografias e trabalhos/documentos técnicos. Um banco de dados foi criado para armazenar as referências coletadas em três planilhas diferentes: a primeira com informações gerais sobre as referências, a segunda com o resumo da referência, e a terceira com informações obtidas através de uma categorização dos documentos em relação à (i) região do país onde se localiza o caso documentado, (ii) macroecossistemas em cada caso, (iii) tipo de arranjo institucional proposto ou estabelecido para cada caso, (iv) principais classes de recursos manejados, e (v) fase da gestão em que se encontra o caso estudado. 


\section{Resultados e discussão}

\section{Formas de Gestão Participativa da Pesca no Brasil}

Os processos de gestão participativa da pesca estão ocorrendo de diversas formas no Brasil. Há processos participativos ocorrendo dentro de Unidades de Conservação de Proteção Integral (como Parque Nacional, Parque Estadual, e Reservas Biológicas), dentro de Unidades de Conservação de Uso Sustentável (como Reserva Extrativista, Reserva Extrativista Marinha, Reserva de Desenvolvimento Sustentável, Área de Proteção Ambiental e Floresta Nacional), e fora de Unidades de Conservação como os Acordos de Pesca e Manejo Comunitário de Lagos na Amazônia, os Fóruns de cogestão na região Sul, e demais processos de gestão participativa da pesca em águas interiores e costeiras no Brasil (Tabela 1).

TABELA 1 - ARRANJOS INSTITUCIONAIS RELACIONADOS À GESTÃO DE RECURSOS PESQUEIROS, ENTRE OUTROS, NO BRASIL.

\begin{tabular}{ll}
\hline ARRANJOS & DEFINIÇÃO \\
\hline Parque Nacional & Unidade de Conservação de Proteção Integral (SNUC ${ }^{1}$, Lei 9985/2000), cujo objetivo é a preser- \\
& vação de ecossistemas naturais de grande relevância ecológica e beleza cênica, possibilitando a \\
& realização de pesquisas científicas e o desenvolvimento de atividades de educação e interpretação \\
& ambiental, de recreação em contato com a natureza e de turismo ecológico. É admitido apenas o uso \\
& indireto dos seus recursos naturais, com exceção dos casos previstos na lei. Os Parques Nacionais \\
& são de posse e domínio públicos, sendo que as áreas particulares incluídas em seus limites devem ser \\
& desapropriadas de acordo com a legislação. A visitação pública dessas áreas está sujeita às normas e \\
& restrições estabelecidas no Plano de Manejo da unidade, às normas estabelecidas pelo órgão respon- \\
& sável por sua administração, e àquelas previstas em regulamento. A pesquisa científica depende de \\
& autorização prévia do órgão responsável pela administração da unidade e está sujeita às condições e \\
& restriçôes por este estabelecidas, bem como àquelas previstas em regulamento.
\end{tabular}

Parque Estadual ou Municipal

Reserva Biológica (REBIO)

Floresta Nacional (FLONA)
Unidades de conservação equivalentes ao Parque Nacional, porém criadas pelo Estado ou Município (Artigo $11^{\circ}$, Parágrafo $4^{\circ}$, da Lei 9985/2000, SNUC)

Unidade de Conservação de Proteção Integral, cujo objetivo é a preservação integral da biota e demais atributos naturais existentes em seus limites, sem interferência humana direta ou modificações ambientais, excetuando-se as medidas de recuperação de seus ecossistemas alterados e as ações de manejo necessárias para recuperar e preservar o equilíbrio natural, a diversidade biológica e os processos ecológicos naturais. Assim como os Parques Nacionais, as Reservas Biológicas são de posse e domínio públicos, sendo que as áreas particulares incluídas em seus limites devem ser desapropriadas de acordo com a legislação. A pesquisa científica depende de autorização prévia do órgão responsável pela administração da unidade e está sujeita às condições e restrições por este estabelecidas, bem como àquelas previstas em regulamento. A visitação pública é proibida a não ser que tenha objetivo educacional e esteja de acordo com regulamento específico.

Área com cobertura florestal de espécies predominantemente nativas que tem como objetivo básico o uso múltiplo sustentável dos recursos florestais e a pesquisa científica, com ênfase em métodos para exploração sustentável de florestas nativas. Por serem Unidades de Conservação de Uso Sustentável é admitida a permanência de populações tradicionais que habitam as Florestas Nacionais quando de sua criação, em conformidade com o disposto em regulamento e no Plano de Manejo da unidade. Porém, as áreas particulares incluídas em seus limites que não estejam relacionadas às populações tradicionais devem ser desapropriadas. A visitação pública é permitida, condicionada às normas estabelecidas para o manejo da unidade pelo órgão responsável por sua administração. A pesquisa não apenas é permitida como incentivada, sujeitando-se à prévia autorização e às condições do órgão responsável pela administração da unidade. O SNUC estabelece que cada Floresta Nacional disporá de um Conselho Consultivo, presidido pelo órgão responsável por sua administração e constituído por representantes de órgãos públicos, de organizações da sociedade civil e, quando for o caso, das populações tradicionais residentes. 


\section{ARRANJOS DEFINIÇÃO}

Área de Proteção

Ambiental (APA)

Reserva Extrativista (RESEX) e Reserva Extrativista Marinha (RESEX-MAR)

Reserva de Desenvolvimento Sustentável (RDS)

Acordos de pesca

Manejo comunitário de lagos na Amazônia

Cooperativas

Fóruns de pesca
Unidade de Conservação de Uso Sustentável destinada a resolver conflitos de uso, proteger a diversidade biológica, disciplinar o processo de ocupação e assegurar a sustentabilidade do uso dos recursos naturais. As APAs são constituídas de terras públicas e privadas, devendo dispor de um conselho "presidido pelo órgão responsável por sua administração e constituído por representantes dos órgãos públicos, de organizações da sociedade civil e da população residente, conforme se dispuser no regulamento desta Lei" (SNUC, Parágrafo $5^{\circ}$ ).

Unidades de Conservação de Uso Sustentável destinada à proteção dos recursos naturais e à melhoria das condições de vida das comunidades a elas associadas. RESEXs são áreas de domínio público, concedida às populações tradicionais, necessitando, portanto, de desapropriação de áreas particulares. Devem ser regidas por um conselho deliberativo que tem como primeira função aprovar o plano de manejo. A RESEX Marinha constitui-se de uma Reserva Extrativista voltada para a proteção dos recursos naturais e populações tradicionais da faixa litorânea.

Unidade de Conservação de Uso Sustentável que abriga populações tradicionais cuja existência se baseia em sistemas sustentáveis de exploração dos recursos naturais e que desempenham um papel fundamental na proteção da natureza e da biodiversidade. Na RDS as desapropriações não são obrigatórias, mas podem ocorrer. Deve ser regida por um conselho deliberativo, sendo também necessária a aprovação do plano de manejo, que "definirá as zonas de proteção integral, de uso sustentável e de amortecimento e corredores ecológicos" (Art. 20 do SNUC, Parágrafo $6^{\circ}$ ).

São acordos realizados entre os pescadores da região amazônica com o objetivo de regular a pesca nos seus rios e lagos. São regulamentados pela Instrução Normativa (IN n 29/03) do IBAMA. Estes arranjos têm o objetivo de definir as regras de acesso e de uso dos recursos pesqueiros numa determinada região, elaboradas pela própria comunidade e demais usuários. Não preveem desapropriação de área, somente aspectos de uso e exploração dos recursos.

Manejo pesqueiro realizado por comunidades ribeirinhas organizadas formalmente ou informalmente, visando o controle do acesso aos lagos na Amazônia e do uso de seus recursos pesqueiros, para manutenção de suas fontes de renda e de alimentação. O manejo comunitário de lagos era uma prática feita tradicionalmente pelas comunidades da Amazônia. Desde a década de 1960, com apoio da igreja católica, essas comunidades começaram a se organizar melhor e a requerer seus direitos. Como resultado, há diversos casos em que o IBAMA legitimou as práticas comunitárias de manejo, por meio da implementação dos Conselhos Regionais de Pesca e da transformação dos acordos de pesca em portarias. Estes Conselhos são compostos de representantes de todas as comunidades localizadas em torno de um sistema de lagos, consistindo na instituição responsável pela elaboração e implementação dos acordos de pesca.

As cooperativas são instituições comerciais da sociedade civil, sem fins lucrativos, que possuem o objetivo de prestar serviços geralmente de interesse econômico, técnico, legal e político aos seus associados, viabilizando e desenvolvendo sua atividade produtiva. Como estratégia para alcançar uma maior independência financeira dos atravessadores (compradores intermediários), as cooperativas surgem como uma forma de organização entre os pescadores e extratores de diversas localidades no Brasil, visando formas de comercialização mais favoráveis de seus produtos, gerando, assim, maior desenvolvimento socioeconômico dessas classes.

São arranjos não regulamentados que surgem da organização da comunidade e sua necessidade de discutir problemas e buscar soluções. São espaços de debate entre as representatividades diversas que possuem interesse na pesca.

\footnotetext{
${ }^{1}$ Sistema Nacional de Unidades de Conservação da Natureza.
} 
Comparando os arranjos encontrados no Brasil com a classificação proposta por Sen e Nielsen (1996), observamos que há áreas onde, de acordo com a legislação vigente, deveria ocorrer apenas a gestão instrutiva, mas, na prática, estão ocorrendo processos mais participativos (ou estes estão sendo recomendados por cientistas, ou pressionados pelas populações tradicionais), como no caso das experiências em Unidades de Conservação de Proteção Integral. Em muitos dos casos, isto ocorre porque tais Unidades de Conservação de Proteção Integral foram instaladas onde previamente viviam populações humanas consideradas tradicionais.

Com relação às Unidades de Conservação de Uso Sustentável, observamos que, de acordo com a legislação, em algumas instâncias, como em Florestas Nacionais, deve ocorrer a gestão consultiva, mas em outras instâncias deve ocorrer a gestão compartilhada, como no caso das Reservas Extrativistas e Reservas de Desenvolvimento Sustentável. Na prática, no entanto, os instrumentos de gestão consultiva (Conselhos Consultivos) e de gestão compartilhada (Conselhos Deliberativos) ainda são embrionários na maioria das experiências documentadas. Isto pode estar relacionado com o fato de que, embora a Lei que instituiu o Sistema Nacional de Unidades de Conservação da Natureza (SNUC) seja de 2000, apenas em 2007 (i.e., após o término de nossa coleta de dados) foi publicada a Instrução Normativa (IN 02, Instituto Chico Mendes) que disciplina as diretrizes, normas e procedimentos para formação e funcionamento dos Conselhos Deliberativos.

A gestão por aconselhamento é verificada, por exemplo, nos Acordos de Pesca elaborados por comunidades de pescadores da Amazônia e transformados em Instrução Normativa pelo Instituto Brasileiro do Meio Ambiente e dos Recursos Naturais Renováveis (IBAMA). Já a gestão informativa é, até onde sabemos, inexistente no Brasil; isto é, de acordo com a legislação referente ao uso e gestão de recursos pesqueiros, o governo sempre deve ou (i) tomar decisões (após consulta ou não aos usuários), ou (2) compartilhar as decisões, ou (3) retificar as decisões tomadas pelos usuários, mantendo o direito de não aprovar alguma delas. Há casos, entretanto, em que regras informais de uso e acesso aos recursos são desenvolvidas localmente e, por um motivo ou outro, não são retificadas pelo governo. Estes são casos de manejo comunitário que se iniciaram geralmente antes da criação da Superintendência do Desenvolvimento da Pesca (SUDEPE), em 1967, a qual fortaleceu a presença do Estado na gestão da pesca e erodiu muitos desses sistemas tradicionais, que acabaram desaparecendo ou se modificando ao longo do tempo, principalmente na região costeira. Exemplos destes últimos são descritos por Cordell e McKean (1992) para a comunidade de Valença no sul da Bahia, por Pinto da Silva (2004) para a comunidade de Arraial do Cabo (RJ), por Seixas e Berkes (2003) para a Lagoa de Ibiraquera, no litoral sul de Santa Catarina; por Almudi (2005) na Lagoa do Peixe e por Kalikoski e Vasconcellos (2007) na Lagoa dos Patos, ambos no litoral sul do Rio Grande do Sul.

\section{Experiências, projetos e propostas de gestão participativa da pesca no Brasil}

A Tabela 2 apresenta estudos de casos relacionados à gestão participativa da pesca no Brasil de acordo com as formas de arranjos institucionais, a região do país e as referências bibliográficas que os citam. A Tabela 3 apresenta os demais trabalhos de divulgação, teóricos ou relacionados à gestão pesqueira ou uso de recursos pesqueiros no Brasil. Uma análise destas duas tabelas mostra alguns fatos e lacunas que devem ser considerados no desenvolvimento de políticas pesqueiras e de políticas de fomento a pesquisa. 


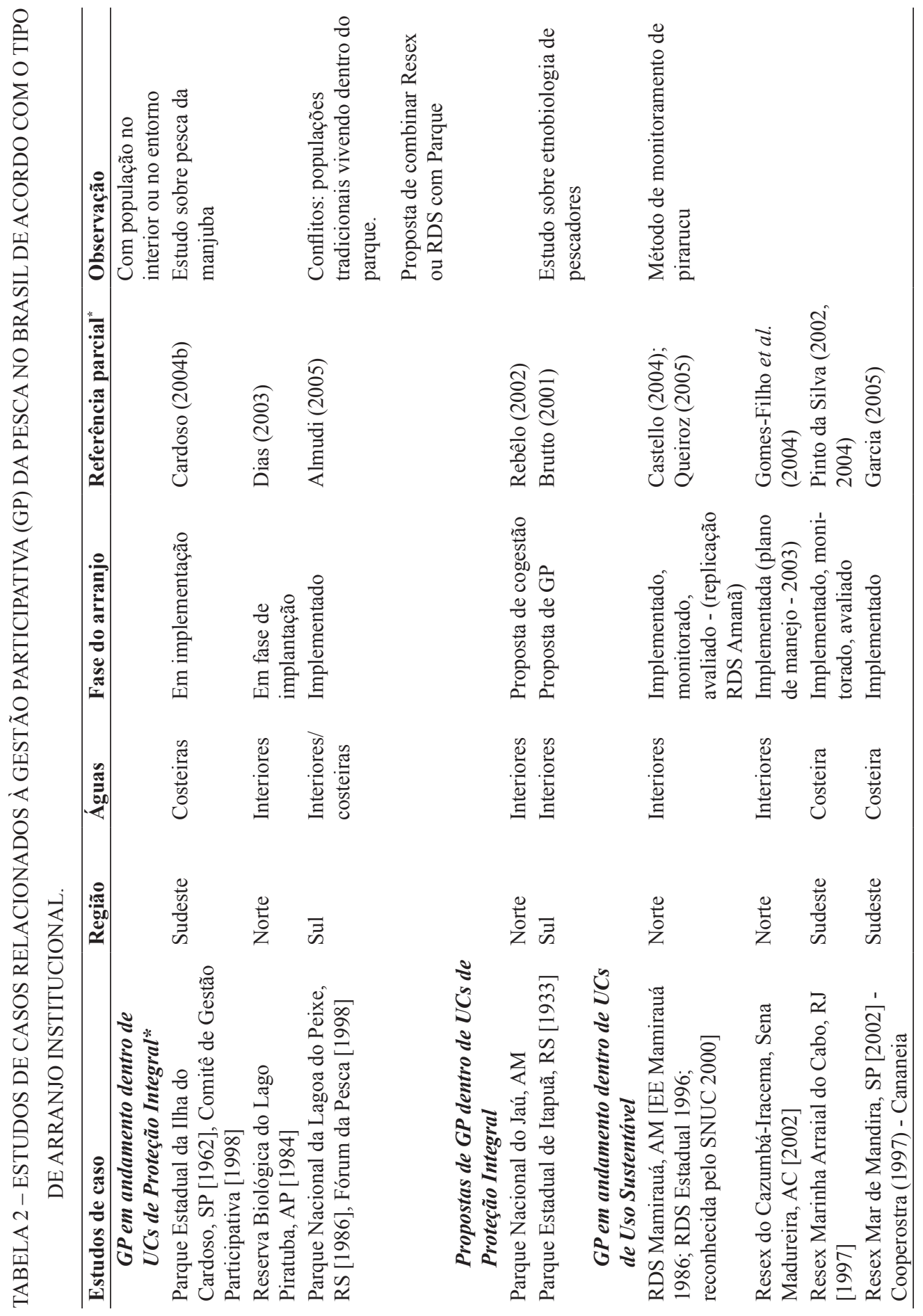




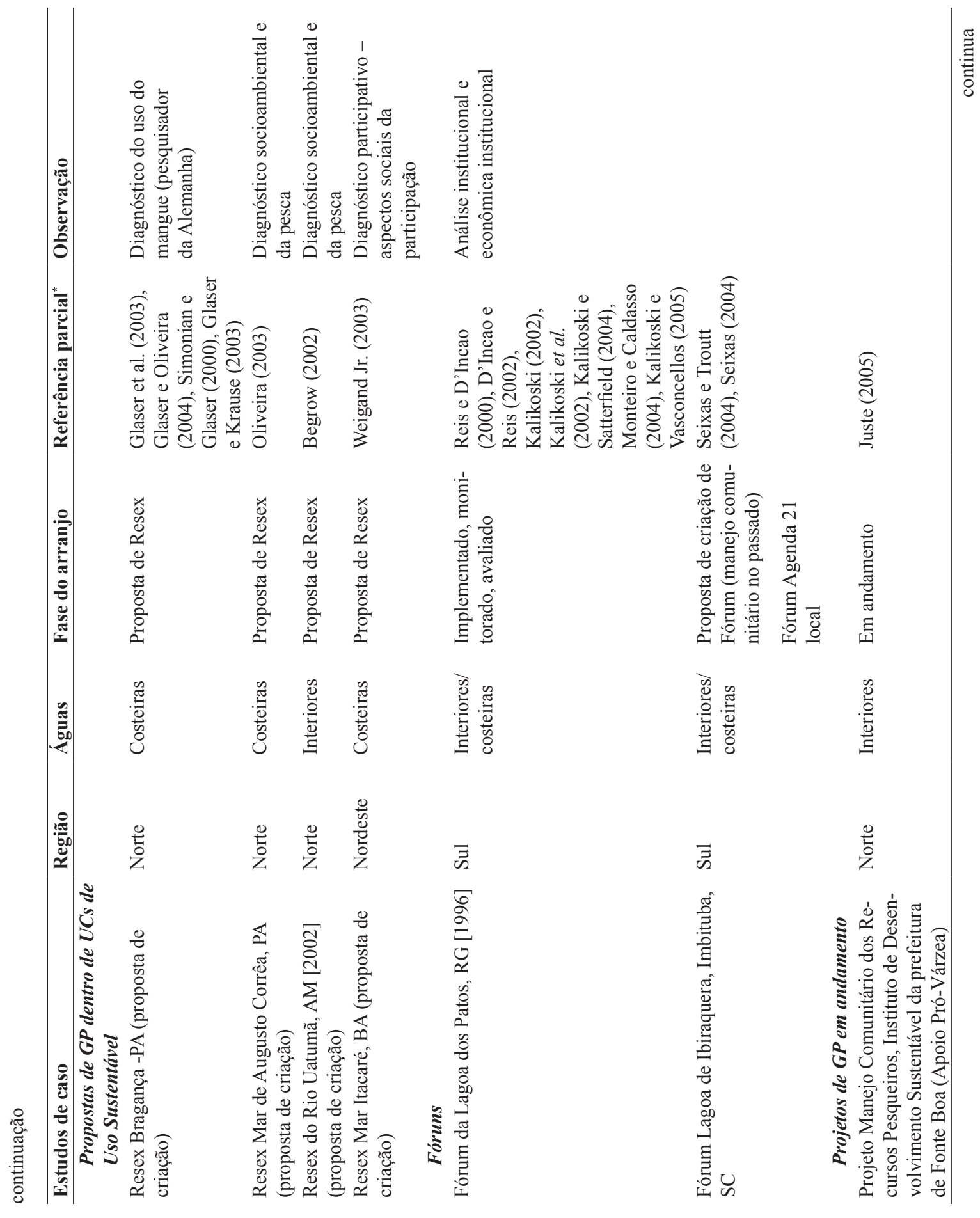




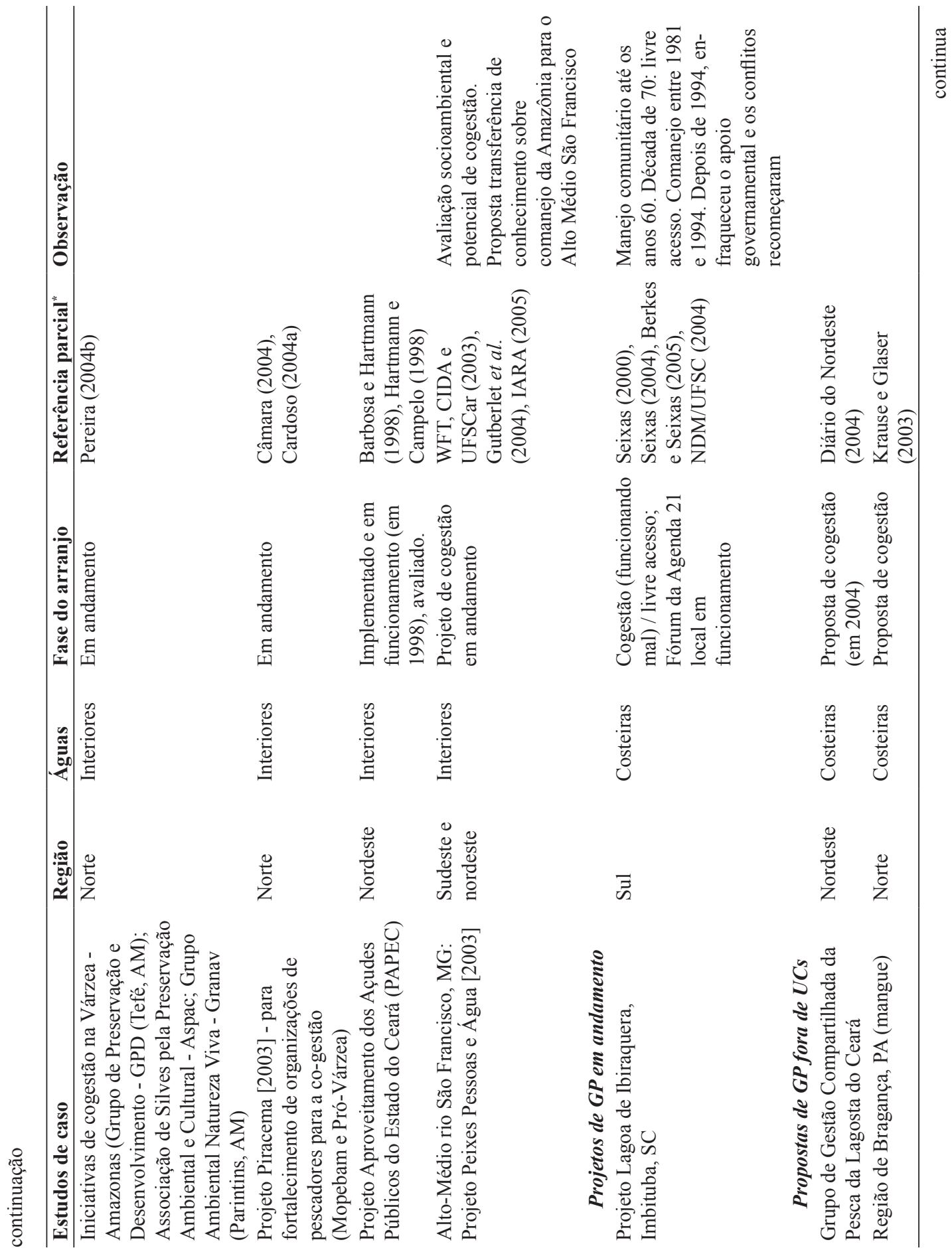




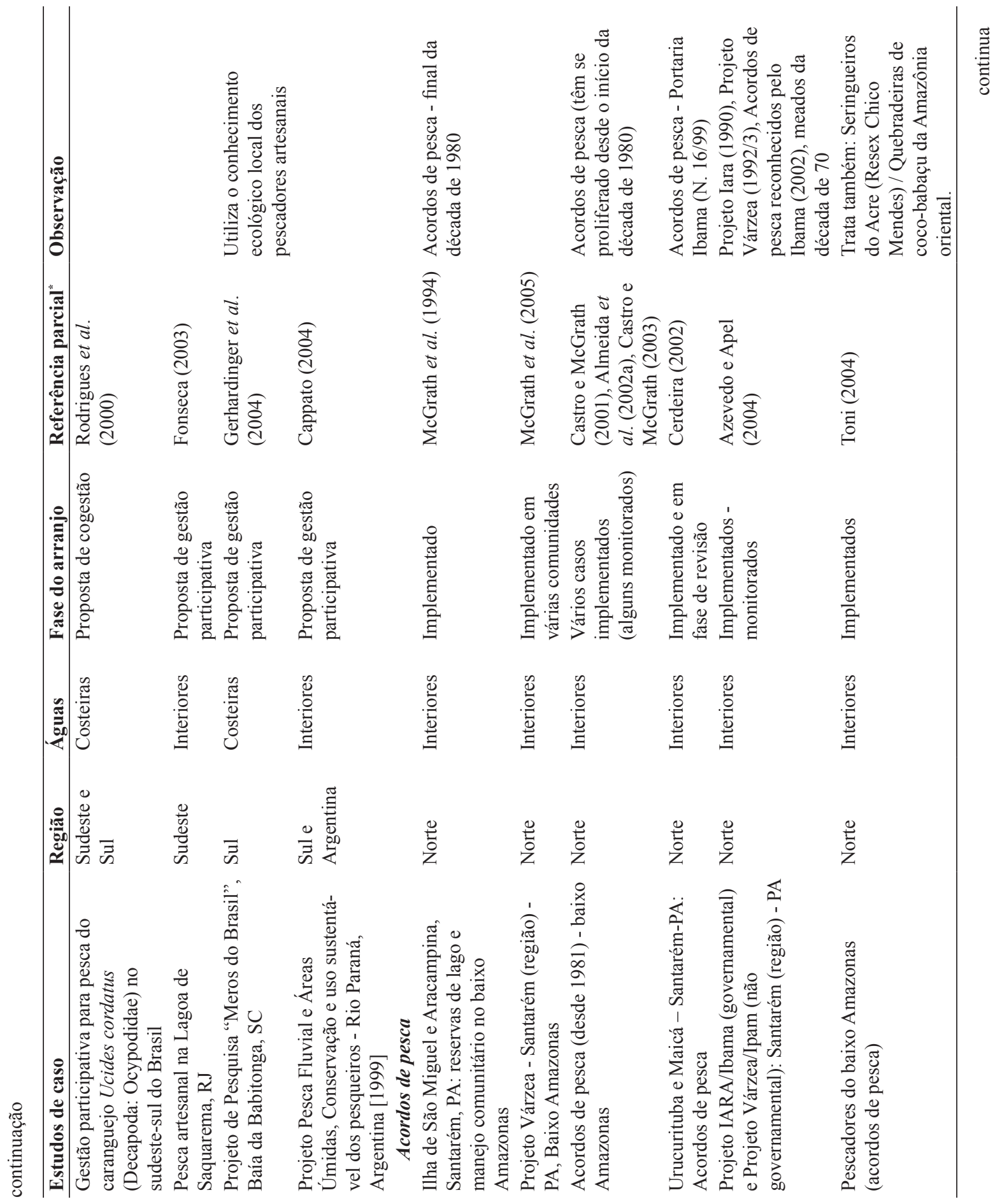




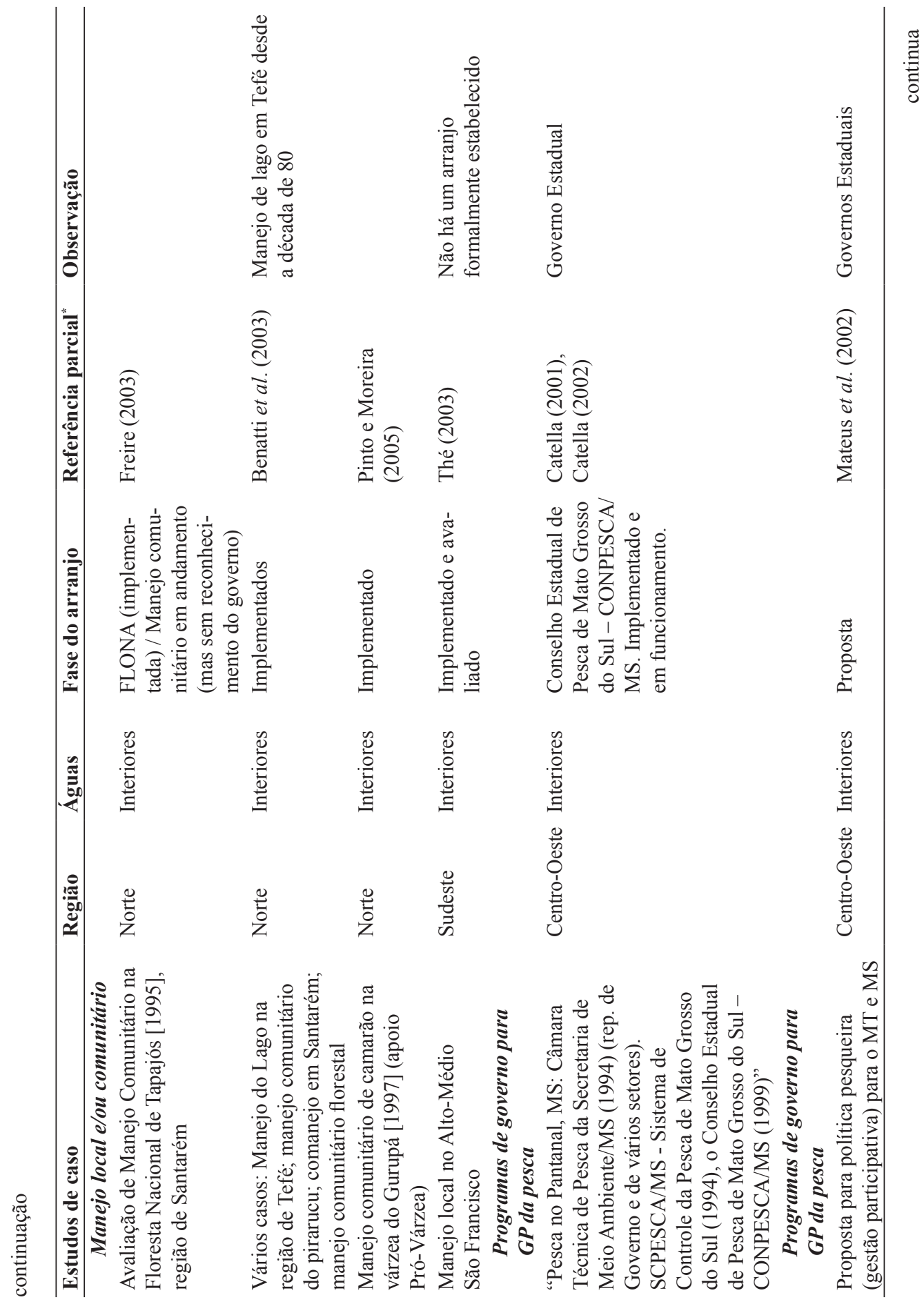




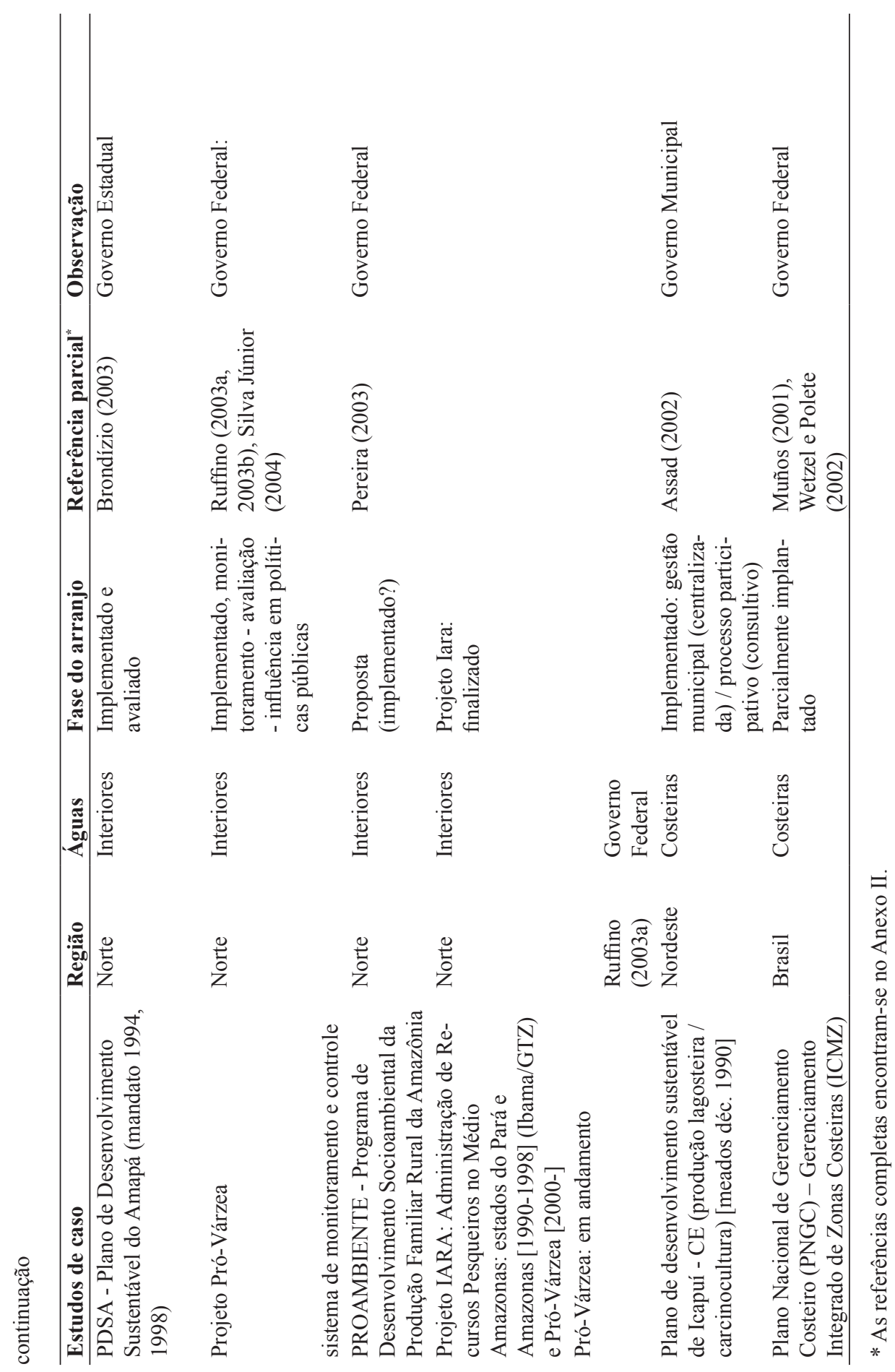


TABELA 3 - DEMAIS TRABALHOS DE DIVULGAÇÃO, TEÓRICOS OU RELACIONADOS À GESTÃO PESQUEIRA.

\begin{tabular}{|c|c|c|c|}
\hline Outros trabalhos & Região & Águas & Referência parcial* $^{*}$ \\
\hline \multicolumn{4}{|l|}{$\begin{array}{l}\text { Trabalhos teóricos - manejo comunitário e/ou } \\
\text { acordos de pesca }\end{array}$} \\
\hline Proposta de reservas de lago como unidades de manejo & Norte & Interiores & McGrath et al. (1996) \\
\hline $\begin{array}{l}\text { Avaliação e monitoramento de impactos dos acordos de pesca } \\
\text { [início da déc. 1970] na região do Médio Amazonas: } \\
\text { região de Santarém, PA }\end{array}$ & Norte & $\begin{array}{l}\text { Águas } \\
\text { interiores }\end{array}$ & Isaac e Cerdeira (2004) \\
\hline Manejo comunitário do pirarucu & Norte & Interiores & Damasceno (2004) \\
\hline \multicolumn{4}{|l|}{ Trabalhos de divulgação sobre comanejo } \\
\hline Cogestão na Amazônia & Norte & Interiores & Pereira $(2004 a)$ \\
\hline Análise de comanejo pesqueiro na Amazônia & Norte & Interiores & Oviedo e Bursztyn (2004) \\
\hline \multicolumn{4}{|l|}{ Pesqueiros na Amazônia } \\
\hline $\begin{array}{l}\text { Acordos de pesca (ocorrem há anos) e participação de agentes } \\
\text { ambientais voluntários na região de Parintins - Apoio Pró-Várzea }\end{array}$ & Norte & Interiores & Aquino e Lima (2004) \\
\hline \multicolumn{4}{|l|}{ Trabalhos sobre pesca e/ou recursos pesqueiros } \\
\hline A pesca e os recursos pesqueiros na Amazônia brasileira (livro) & Norte & Interiores & Ruffino (2004) \\
\hline Análise de pesca comercial (não é sobre comanejo) & Norte & Interiores & Almeida et al. (2003) \\
\hline Peixes migratórios da Amazônia & Norte & Interiores & Araujo-Lima e Ruffino (2004) \\
\hline Avaliação sobre o ordenamento da pesca marítima no Brasil & Brasil & Costeiras & Lima e Neto (2002) \\
\hline Análise bioeconômica das políticas pesqueiras na Amazônia & Norte & Interiores & Lorenzen et al. (2005) \\
\hline Trabalho sobre territorialidade e pesca & Brasil & Costeiras & Cardoso (2001) \\
\hline Avaliação de estoque de caranguejo - Caeté & Norte & Costeiras & Diele et al. (2005) \\
\hline $\begin{array}{l}\text { Etnoconhecimento de pescadores da Amazônia: Manaus e } \\
\text { Manacapuru, AM }\end{array}$ & Norte & Interiores & Lima (2003) \\
\hline Utilização do conhecimento ecológico para o manejo & Sudeste & $\begin{array}{l}\text { Interiores/ } \\
\text { costeiras }\end{array}$ & Begossi (2004) \\
\hline Etnoconhecimento de pescadores do Vale do Ribeira & Sudeste & Costeiras & Souza (2004) \\
\hline \multicolumn{4}{|l|}{ Unidades de Conservação onde há pesca } \\
\hline Reservas Extrativistas (teórico) e Resex Bragança, PA & Norte & $\begin{array}{l}\text { Interiores/ } \\
\text { costeiras }\end{array}$ & Simonian e Glaser (2000) \\
\hline Mosaicos de Unidades de Conservação & $\begin{array}{l}\text { Sudeste e } \\
\text { Sul }\end{array}$ & Costeiras & Ferreira et al. (2004) \\
\hline Escalas de interação: usuários, recursos e instituições. Ex. Resex & $\begin{array}{l}\text { Sudeste e } \\
\text { Norte }\end{array}$ & $\begin{array}{l}\text { Interiores/ } \\
\text { costeiras }\end{array}$ & Begossi (1999) \\
\hline
\end{tabular}

*As referências completas encontram-se no Anexo II. 
Há mais estudos e projetos de implementação de processos de gestão participativa da pesca na região Norte, em particular no Estado do Amazonas e na região de Santarém, Pará, do que em qualquer outra região do Brasil. E mesmo os trabalhos mais teóricos sobre manejo comunitário e cogestão da pesca utilizam os exemplos da Amazônia e em particular os "acordos de pesca". Os "acordos de pesca" são os arranjos institucionais mais estudados e promovidos por políticas pesqueiras e projetos de pesquisa-ação na região Amazônica. Esses acordos são regras de uso e acesso aos recursos pesqueiros em uma determinada área (geralmente um lago de várzea), decididas localmente e retificadas pelo IBAMA por meio de portarias específicas.

Os fóruns de cogestão da pesca são instituições que promovem interações interescalares (de organizações locais a federais) que discutem além da pesca artesanal a complexidade de interações desta com outros setores econômicos como o turismo, a indústria, a pesca industrial. O Fórum da Lagoa dos Patos, RS, tem sido o mais estudado até o momento e é, sem, dúvida o que abrange a maior área de gerenciamento.

É interessante notar que parece haver um aprendizado mais regionalizado sobre formas possíveis de gestão participativa fora de Unidades de Conservação. Por exemplo, os acordos de pesca são descritos quase que exclusivamente para a região amazônica e a única experiência documentada de se criar acordos de pesca fora desta região foi por meio de um projeto no Alto-Médio São Francisco que se empenhou em transferir as lições aprendidas na Amazônia para a região sudeste pelo intercâmbio de pesquisadores, extensionistas e pescadores. Da mesma forma, os Forúns são descritos apenas para a região sul do Brasil.

Outra observação feita neste estudo é que há mais que o dobro de pesquisas sobre experiências, projetos e programas de gestão participativa para águas interiores (29) do que para águas costeiras (12) e mistas (interiores/costeiras) (3). Sabemos, entretanto, que existem muito mais casos no litoral brasileiro onde estão ocorrendo processos de gestão participativa da pesca, tais como os projetos financiados pelo Fundo Nacional do Meio Ambiente em 2003 e 2005. No entanto, se há pesquisas realizadas sobre estes casos, e estas parecem não estarem sendo bem divulgadas. Em relação às águas interiores, com exceção da Bacia do Rio Amazonas e mais recentemente a Bacia do Rio São Francis- co (sudeste/nordeste), praticamente não há pesquisas sobre gestão participativa da pesca: em especial, nota-se a falta de estudos sobre a Bacia do Prata e em particular sobre a sub-bacia do Rio Paraná.

Com relação à gestão participativa da pesca em Unidades de Conservação de Uso Sustentável, sem dúvida a Reserva de Desenvolvimento Sustentável (RDS) de Mamirauá (a primeira criada no Brasil) tem sido a mais estudada de todas. Não encontramos, no entanto, pesquisas realizadas em qualquer outra RDS. A despeito do enorme número de reservas extrativistas marinhas (ResexMar) que estão sendo criadas no Brasil, também há pouquíssimos estudos (p. ex. LOBÃO, 2000; PINTO DA SILVA, 2004) avaliando os resultados sociais e ambientais da criação destas unidades. Há alguns estudos, porém, sobre diagnósticos socioambientais realizados para apoiar a criação de ResexMar.

É válido ressaltar que mesmo em Unidades de Conservação de Proteção Integral onde há população humana vivendo dentro ou no seu entorno, já existem alguns processos de gestão participativa. O número que encontramos desses casos, entretanto, é ínfimo (apenas 3) em vista do total de Unidades de Proteção Integral federais, estaduais e municipais existente em cada região.

Considerando os programas do governo federal que promovem a gestão participativa da pesca, observamos que os três programas/projetos documentados são concentrados na região Amazônica. Para região costeira, existe o Programa Nacional de Gerenciamento Costeiro (PNGC) que contempla a participação de pescadores, entre outros inúmeros usuários das regiões costeiras, em audiências públicas consultivas. Mas parece haver uma lacuna na documentação dos processos regionais de gerenciamento costeiro ocorrendo no Brasil, ou as palavras chaves que utilizamos em nosso levantamento não foram suficientes para detectar tal documentação.

Notamos que há vários estudos de cunhos diversos e diagnósticos socioambientais realizados em diferentes regiões do Brasil que sugerem a criação de processos participativos para gestão da pesca dentro e fora de Unidades de Conservação. Ou seja, parece existir uma visão crescente entre estudiosos de que o processo de gestão participativa é mais eficaz do que o processo centralizador de gestão da pesca que ocorre na maior parte do Brasil. 


\section{Publicações relacionadas à gestão participativa da pesca no Brasil}

Com relação ao total de referências que fazem menção, mesmo que indiretamente, a processos de gestão participativa da pesca, notamos que (i) há mais de três publicações sobre processos na região norte para cada publicação sobre processos na região sul, sudeste e nordeste; (ii) há cerca de $40 \%$ a mais de publicações sobre a região norte do que a soma de todos as outras regiões; e, (iii) a região mais deficiente de informações é o centro-oeste (Tabela 4). É claro que o número de publicações não deve ser necessariamente relacionado ao número de experiências, pois há pesquisadores que publicam mais que outros. Entretanto, neste estudo, os dados de publicação corroboram com os dados de estudos de caso (Tabela 1) de que há muito mais iniciativas de gestão participativa na região norte do que em qualquer outra região do Brasil.

TABELA 4 - NÚMERO DE REFERÊNCIAS BIBLIOGRÁFICAS QUE MENCIONAM PROCESSOS DE GESTÃO PARTICIPATIVA DA PESCA EM CADA REGIÃO DO BRASIL.

\begin{tabular}{lccccccccc}
\hline & \multicolumn{1}{c}{ Regiões } & \multicolumn{7}{c}{ 2 ou } \\
Principais recursos & N & NE & SE & S & CO & + & Brasil TOTAL \\
Recursos pesqueiros & 42 & 7 & 8 & 13 & 3 & 6 & 2 & 81 \\
$\begin{array}{l}\text { Recursos terrestres e } \\
\text { aquáticos (mangue) }\end{array}$ & 8 & 3 & & 1 & & 2 & 2 & 16 \\
Subtotal & 51 & 10 & 8 & 14 & 3 & 8 & 4 & 97 \\
\hline
\end{tabular}

\section{Considerações finais}

Parece estar havendo um crescente consenso entre pesquisadores de diversas disciplinas acadêmicas e regiões do Brasil de que a gestão participativa da pesca é mais promissora do que o modelo de gestão centralizada que esteve presente nas últimas décadas na maior parte deste país. De fato, o envolvimento de pescadores e outros usuários na gestão dos recursos está sendo recomendado por diversos cientistas e gestores para diferentes arranjos institucionais. Entretanto, ainda não há um esforço de se avaliar como estes diferentes arranjos institucionais, legais ou não, de gestão participativa da pesca influenciam a conservação dos recursos pesqueiros e os modos e qualidade de vida dos pescadores. Para sanar tal lacuna no conhecimento (e na prática), propomos:

1. Criar uma rede de pesquisadores que estudam gestão participativa da pesca a fim de promover troca de experiências e lições aprendidas e sistematizar a coleta de algumas informações importantes para uma avaliação global dos arranjos institucionais e suas implicações.

2. Criar Centros de Excelência em pesquisa e capacitação sobre gestão participativa da pesca a fim de: devenvolver pesquisas inovadoras, em particular sobre cogestão adaptativa (ARMITAGE et al., 2007); formar novos pesquisadores e incentivá-los a documentar e divulgar suas pesquisas; e capacitar gestores e usuários de recursos (principalmente pescadores) para engajar em processos de gestão participativa da pesca.

3. Criar um Programa Nacional de Gestão Participativa da Pesca junto ao governo federal que:

a. incentive a gestão participativa da pesca, principalmente nas regiões mais deficientes neste tipo de iniciativas;

b. promova a troca de lições aprendidas entre gestores, pescadores e pesquisadores por meio de intercâmbio de pessoas, reuniões, visitas guiadas etc.;

c. fomente a pesquisa sobre (i) os processos de gestão participativa, principalmente de gestão compartilhada da pesca, e (ii) os resultados (monitoramento) obtidos em cada iniciativa;

d. desenvolva estratégias de disseminação dos resultados das pesquisas para diferentes audiências: por ex.: pescadores, demais usuários, gestores municipais, estaduais e federais, organizações não governamentais, empresários.

\section{Agradecimentos}

Uma versão expandida deste trabalho foi desenvolvida para o Workshop "Gestão Compartilhada de Recursos Pesqueiros no Brasil" realizado de 03 a 05 de maio de 2006, em Tamandaré-PE, na sede do Centro de Pesquisas em Recursos Pesqueiros do Nordeste (CEPENE/IBAMA). As 
autoras agradecem ao International Development Reserach Center (IDRC-Canada) por ter financiado o desenvolvimento desse trabalho, especialmente ao Dr. Brian Davy do International Institute for Sustainable Development (IISD)

\section{Referências}

ALMUDI, T. Adequação do modelo de unidade de conservação: populações humanas, convivências e conflitos nos arredores da Lagoa do Peixe (RS). Monografia - Fundação Universidade Federal do Rio Grande (FURG), Rio Grande. 188p. 2005.

ARMiTAGE, D.; F. BERKES; DOUBLEDAY, N. (Eds). Adaptive Co-Management: Collaboration, Learning, and Multi-Level Governance. Vancouver: University of British Columbia Press. 2007

BERKES F.; MAHON R.; MCCONNEY P.; POLLNAC R.B.; POMEROY R.S. Managing Small-scale Fisheries. Ottawa: International Development Research Center (IDRC). 2001.

CORDELL, J.; MCKEAN, M. A. Sea Tenure in Bahia, Brazil. In BROMLEY, D.W. (Ed.), Making the Commons Work: Theory, Practice, and Policy. San Francisco: ICS Press. 1992.

KALIKOSKI, D.C.; SEIXAS, C.S.; ALMUDI, T. Gestão compartilhada e comunitária da pesca no Brasil: Avanços e desafios. Ambiente \& Sociedade (no prelo). pelo seu apoio e sugestões valiosas. Também somos gratas a Tiago Almudi e Estevão C.F. de Souza pelo auxílio no levantamento bibliográfico e pré-análise dos dados.

KALIKOSKI, D.C.; VASCONCELLOS, M. The role of fishers' knowledge in the comanagement of small-scale fisheries in the estuary of Patos Lagoon, Southern Brazil. In HAGGAN, N.; NEIS, B; BAIRD, I. G. (Eds). Fishers' Knowledge in Fisheries Science and Management. Paris: UNESCO Publishing. 2007.

LOBÃO, R.J.S. Reservas Extrativistas Marinhas: Uma reforma agrária do mar? Tese (Mestrado em Antropologia) - Universidade Federal Fluminense. Niterói. 2000.

PINTO DA SILVA, P. From common property to co-management: lessons from Brazil's first maritime extractive reserve. Marine Policy v. 28, n. 5, p. 419-428. 2004.

SEIXAS, C.S.; BERKES, F. Dynamics of social-ecological changes in a Lagoon fishery in Southern Brazil. In: BERKES, F.; COLDING, J.; FOLKE, C. Navigating Social-Ecological Systems: Building Resilience for Complexity and Change. Cambridge: Cambridge University Press. 2003.

SEN S.; NIELSEN J.R. Fisheries co-management: A comparative analysis. Marine Policy, v. 20, n. 5, p. 405-418. 1996 


\section{ANEXO I - SÍTIOS E BANCOS DE DADOS PESQUISADOS NA INTERNET (EM CADA SÍTIO VÁRIAS PÁGINAS FORAM PESQUISADAS NUM TOTAL DE 69)}

\begin{tabular}{|c|c|}
\hline WWF & http://www.wwf.org.br/ \\
\hline Conservation International & http://www.conservation.org/ \\
\hline The Nature Conservancy (TNC) & http://www.tnc.org.br/ \\
\hline Instituto Sócio Ambiental (ISA) & http://www.socioambiental.org/ \\
\hline Instituto de Pesquisa Ambiental da Amazônia (IPAM) & http://www.ipam.org.br/ \\
\hline Núcleo de Altos Estudos Amazônicos (NAEA - UFPA) & http://www2.ufpa.br/naea/ \\
\hline \multicolumn{2}{|l|}{ Os seguintes bancos de dados foram pesquisados } \\
\hline Web of Science & http://www.isiwebofknowledge.com/ \\
\hline Banco de teses da CAPES & http://www.capes.gov.br/servicos/bancoteses.html \\
\hline Portal de Periódicos da CAPES & http://www.periodicos.capes.gov.br/portugues/index.jsp \\
\hline Biological Abstracts & http://scientific.thomson.com/products/ba/ \\
\hline Base de Dados Tropical (BDT) & http://www.bdt.org.br \\
\hline SciELO & http://www.scielo.org/ \\
\hline Science Direct & http://www.sciencedirect.com/ \\
\hline $\begin{array}{l}\text { Bilbioteca da Fundação Universidade Federal do Rio } \\
\text { Grande (FURG) }\end{array}$ & http://www.biblioteca.furg.br/ \\
\hline \multicolumn{2}{|l|}{ Os seguintes sites de busca foram utilizados } \\
\hline Google scholar & http://scholar.google.com.br/ \\
\hline Google & http://www.google.com.br/ \\
\hline \multicolumn{2}{|l|}{ Outro } \\
\hline $\begin{array}{l}\text { CD-Rom: IV Congresso Brasileiro de Unidades de } \\
\text { Conservação }\end{array}$ & \\
\hline
\end{tabular}




\section{ANEXO II - REFERÊNCIAS DOS DOCUMENTOS UTILIZADOS PARAANÁLISE}

ALMEIDA, O. T.; LORENZEN, K.; MCGRATH, D. G. Impact of co-management agreements on the exploitation and productivity of floodplain lake fisheries in the Lower Amazon. BIENNIAL CONFERENCE OF THE INTERNATIONALASSOCIATION FOR THE STUDY OF COMMON PROPERTY (IASCP). Victoria Falls, Zimbabwe. Victoria Falls: IASCP. 2002a. Anais. Disponível em: <http://dlc.dlib.indiana.edu/ archive/00000782/00/almeidao080502.pdf>. Acesso em: jan 2006.

. Oficina de Políticas Pesqueiras para o Baixo Amazonas. IPAM, Santarém, Brasil. 28 p., 2002b. Mimeo. Disponível em: $<\mathrm{http}: / /$ www.aquaticresources.org/pubs/Almeida_etal_2002 Oficina.pdf $>$. Acesso em: jan. 2006.

Commercial fishing in the Brazilian Amazon: regional differentiation in fleet characteristics and efficiency. Fisheries Management and Ecology, v. 10, n. 2, p. 109-115, 2003.

ALMUDI, T. Adequação do modelo de unidade de conservação: populações humanas, convivências e conflitos nos arredores da Lagoa do Peixe (RS). Monografia - Fundação Universidade Federal do Rio Grande (FURG). 188p. Rio Grande. 2005.

AQUINO, A. S.; LIMA, N. S. Acordos de Pesca e Agentes Ambientais Voluntários constroem caminho para o ordenamento pesqueiro em Parintins. Revista Jirau (Informativo do Pró-Várzea/Ibama), v. 5, p. 11-12, 2004.

ARAUJO-LIMA, C. A. R. M.; RUFFINO, M. L. Migratory fishes of the Brazilian Amazon. In: CAROLSFIELD, J.; HARVEY, B.; ROSS, C.; BAER, A. (Ed.). Migratory fishes of South America: Biology, Fisheries, and Conservation Status. Ottawa: IDRC/World Bank. p. 233-301, 2004.

ASSAD, L. T. Tradição-Modernidade-Sustentabilidade: Icapuí/CE: os desafios do desenvolvimento de uma comunidade diante do imperativo da sustentabilidade. Tese (Doutorado) - UnB, Brasília. 200 p. Brasília, 2002.

AZEVEDO, C. R.; APEL, M. Cogestão: Um processo em construção na várzea amazônica. Ibama/ProVárzea, Documentos Técnicos, v. 4, 100 p., 2004.

BARBOSA, F. I.; HARTMANN, W. D. Participatory management of reservoir fisheries in North-Eastern Brazil. FAO Fisheries Technical Paper, n. 374, p. 427-445, 1998.

BEGOSSI, A. Scale of interactions of brazilian populations (caiçaras and caboclos) with resources and institutions. Human Ecology Review, v. 6, n.1, p. 1-7, 1999.
Latin America Fisheries: Local organization and management. In: CONFERENCE OF THE INTERNATINAL SOCIETY FOR ECOLOGICAL ECONOMICS (ISEE), 7. Tunísia, 2002. Anais. Disponível em: <http://neptune.c3ed. uvsq.fr/eee/pages2002isee/paper/p289.pdf.> Acesso em: jan. 2006.

. Artisanal fisheries in the SE Brazilian coast: using fisher information towards local management. 2004. Disponível em: $<$ http://library.witpress.com/pdfs/abstracts/ST04/ST04022AU. pdf $>$. Acesso em: jan. 2006.

BEGROW, A. Bases para um plano de manejo da pesca esportiva para o rio Uatumã - estado do Amazonas - Brasil. Dissertação (Mestrado) - Universidade Federal do Amazonas. 86 p. Manaus, AM, 2002.

BENATTI, J. H.; MCGRATH, D. G.; OLIVEIRA, A. C. M. Políticas Públicas e Manejo Comunitário de Recursos Naturais da Amazônia. Ambiente \& Sociedade, v. 4, n. 2, 2003.

BERKES, F.; SEIXAS, C. S. Building resilience in lagoon social-ecological systems: a local-level perspective. Ecosystems, v. 8, n. 8, p. 967-974, 2005.

BRONDÍZIO, L. S. Gestão de recursos pesqueiros no âmbito do programa de desenvolvimento sustentável do Amapá. Dissertação (Mestrado) - USP. 148p. São Paulo, SP, 2003.

BRUTTO, L. F. G. Ecologia humana e etnoecologia em processos participativos de manejo: o caso do parque de Itapuã, RS e os pescadores artesanais. Dissertação (Mestrado) - UFSCar. 109p. São Carlos, SP, 2001.

CÂMARA, E. P. L. Projeto Piracema acelera ordenamento pesqueiro. Revista Jirau (Informativo ProVárzea/Ibama), v. 7, p. 10-11, 2004.

CAMARGO, S. A. F.; PETRERE Jr., M. Risk analysis applied to the precautionary management of artisanal fisheries in the region of Tucuruí reservoir (Pará, Brazil). Acta Amazonica, v. 34, n. 3, p. 473-485, 2004.

CAPPATO, J. (Coord.). Coalizão Rios Vivos. Projeto Pesca Fluvial e Áreas Úmidas, Conservação e uso sustentável dos pesqueiros - Rio Paraná, Argentina. 2004. Disponível em: $<$ http://www.riosvivos.org.br/canal.php?canal=186>. Acesso em: fev. 2006.

CARDOSO, E. S. Geografia e pesca: aportes para um modelo de gestão. Revista do Departamento de Geografia/USP, v. 14, p. 79-88, 2001. 
CARDOSO, A. M. Sucesso do Projeto Piracema depende de articulação e capacitação das Colônias de Pescadores. Revista Jirau (Informativo ProVárzea/Ibama), n. 7, p. 12, 2004a.

CARDOSO, T. A. Subsidios para o Manejo Participativo da Pesca da Manjuba em duas Comunidades do Parque Estadual da Ilha do Cardoso, SP. Dissertação (Mestrado) - Universidade Federal de São Carlos (UFSCar). 101p. São Carlos, 2004b.

CASTELLO, L. A method to count pirarucu Arapaima gigas: fishers, assessment, and management. North American Journal of Fisheries Management, v. 24, n. 2, p. 379-389, 2004.

CASTRO, F.; MCGRATH, D. O manejo comunitário de lagos na Amazônia. Parcerias Estratégicas, n. 12, 2001.

. Moving toward sustainability in the local management of floodplain lake fisheries in the Brazilian Amazon. Human Organization, v. 62, n. 2, p. 123-133, 2003.

CATELlA, A. C. O monitoramento da pesca no Pantanal do MS. Embrapa Pantanal ADM - Artigo de Divulgação na Midia, n. 7, p. 1-4, 2001.

A pesca no pantanal de Mato Grosso do Sul, Brasil: descrição, nível de exploração e manejo (1994-1999). Tese (Doutorado) - Instituto Nacional de Pesquisas da Amazônia (INPA). 343 p. Manaus, AM, 2002.

CERDEIRA, R. G. P. Acordos de Pesca, alternativa para manejo de recursos pesqueiros. Relatório de Atividades do Projeto. Instituto Amazônico de Manejo Sustentável dos Recursos Ambientais (IARA), Santarém, PA, 2002. Disponível em: $<$ http://idrinfo.idrc.ca/archive/corpdocs/117887/p-100.pdf $>$. Acesso em: jan. 2006.

DAMASCENO, J. M. B. Os desafios para a implantação do manejo comunitário do pirarucu. Revista Jirau (Informativo ProVárzea/Ibama), v. 7, p. 3, 2004.

DIÁRIO DO NORDESTE. A crise da pesca da lagosta chegou a um ponto crítico. Economia. 30/08/2004.

DIAS, T. C. A. C. Gestão participativa: uma alternativa de ecodesenvolvimento para a Reserva Biológica do lago Piratuba/Amapá. Dissertação (Mestrado) - UnB. 144p. Brasília, DF, 2003.

DIELE, K.; KOCH, V.; SAINT-PAUL, U. Population structure, catch composition and CPUE of the artisanally harvested mangrove crab Ucides cordatus (Ocypodidae) in the Caete estuary, North Brazil: indications for overfishing? Aquatic Living Resources, v. 18, n. 2, p. 169-178, 2005.
D'INCAO, F.; REIS, E. G. Community-based management and technical advice in Patos Lagoon estuary (Brazil). Ocean \& Coastal Management, v. 45, n. 8, p. 531-539, 2002.

FERREIRA I. V.; PRATES, A. P. L.; KARAM, K. F.; COELHO, B. H. Mosaicos de unidades de conservação no Brasil: os casos de Santa Catarina, Rio de Janeiro e São Paulo-Paraná. In: CONGRESSO BRASILEIRO DE UNIDADES DE CONSERVAÇÃO, 4. Curitiba, 2004. Anais, CD-ROM.

FONSECA, R. A. A. Atividade pesqueira artesanal na Lagoa de Saquarema, RJ: uma investigação junto aos pescadores como subsídio para um plano de gestão participativa. Dissertação (Mestrado) - UFF. 121p. Niterói, RJ, 2003.

FREIRE, R. M. Sistemas locais de apropriação dos recursos e suas implicações para projetos de manejo comunitário: um estudo de caso numa comunidade tradicional da Floresta Nacional do Tapajós - PA. Tese (Doutorado) - Universidade de São Paulo (USP). São Paulo, 2003.

GARCIA, T. R. Impactos da implantação de uma cooperativa de produção de ostras junto a comunidades extrativistas caiçaras do litoral Sul/SP: um estudo de caso. Dissertação (Mestrado) - Universidade de São Paulo (USP). 103 p. São Paulo, 2005.

GERHARDINGER, L. C.; FREITAS, M. O.; MEDEIROS, R. P.; GODOY, E. A.; MARENZI, R. C.; SILVA, M. H. Conhecimento ecológico local e biodiversidade marinha no planejamento de áreas marinhas protegidas: uma análise crítica. In: CONGRESSO BRASILEIRO DE UNIDADES DE CONSERVAÇÃO, 4. Curitiba, 2004. Anais CD-ROM.

GLASER, M.; KRAUSE, G. User-based mangrove comanagement in Brazil. In: Conservation and Sustainable Use of Agricultural Biodiversity: A Sourcebook. CIP-UPWARD, p. 559-363, 2003. Disponível em: <http://www.eseap.cipotato.org/upward/Publications/Agrobiodiversity/pages\%20 559-563\%20(Paper\%2067).pdf>. Acesso em: jan. 2006.

GLASER, M.; OLIVEIRA, R. D. Prospects for the co-management of mangrove ecosystems on the North Brazilian coast: Whose rights, whose duties and whose priorities? Natural Resources Forum, v. 28, n. 3, p. 224-233, 2004.

GLASER, M.; BERGER, U.; MACEDO, R. Local vulnerability as an advantage: mangrove forest management in Pará state, north Brazil, under conditions of illegality. Regional Environmental Change, v. 3, n. 4, p. 162-172, 2003.

GOMES-FILHO, A.; AMARAL, P. P.; CUNHA, C. C.; COSTA, V. A.; SILVA, S. S.; VANDA, E.; DUQUE, A. A. O.; GUIMARÃES, J. Caracterização socioeconômica da Reserva 
Extrativista do Cazumbá-Iracema, Sena Madureira, AC. In: CONGRESSO BRASILEIRO DE UNIDADES DE CONSERVAÇÃO, 4. Curitiba, 2004. Anais CD-ROM.

GUTBERLET, J.; SEIXAS, C. S.; THE, A. P. Challenges in managing fisheries in the São Francisco watershed of Brazil. In: BIENNIAL CONFERENCE OF THE INTERNATIONAL ASSOCIATION FOR THE STUDY OF COMMON PROPERTY (IASCP), 10. Oaxaca, Mexico, 2004. Anais. Disponível em: $<$ http://dlc.dlib.indiana.edu/archive/00001806/01/gutberlet2004.pdf $>$. Acesso em: jan. 2006.

HARTMANN, W. D.; CAMPELO, C. M. F. Ambivalent Enforcers. Rules and Conflicts in the Co-Management of Brazilian Reservoir Fisheries. Crossing Boundaries. In: BIENNIAL CONFERENCE OF THE INTERNATIONALASSOCIATION FOR THE STUDY OF COMMON PROPERTY, 7. Vancouver, Canada, 1998. Anais. Disponível em: <www.indiana. edu/ iascp/Drafts/hartmann.pdf $>$. Acesso em: jan. 2006.

IARA (Instituto Amazônico de Manejo Sustentável dos Recursos Ambientais). Towards Fisheries Co-management in the Sao Francisco River Valley. Projeto. International Development Research Centre. (IDRC). 2005. Disponível em: <http://www. idrc.ca/pt/ev-69633-201_101598-1-IDRC_ADM_INFO. html>. Acesso em: jan 2006 .

ISAAC, V. J.; CERDEIRA, R. G. P. Avaliação e monitoramento de impactos dos acordos de pesca na região do Médio Amazonas. Ibama/PróVárzea, Documentos Técnicos, v. 3, 64 p., 2004.

JUSTE, M. A multiplicação dos peixes, sem milagre. Projeto na Amazônia restabelece estoques de pirarucu ameaçado de extinção e ajuda comunidades da região a ganharem mais. Notícia PNUD, 2005. Disponível em: <www.pnud.org.br/meio_ambiente/reportagens/index.php?id01=1421\&lay $=$ mam $\#>$. Acesso em: fev. 2006.

KALIKOSKI, D. C. The Forum of the Patos Lagoon: An Analysis o Co-Management Arrangement for Conservation of Coastal Resources in Southern Brazil. Ph.D. Thesis - University British Columbia (UBC). Vancouver, Canadá, 2002.

; SATTERFIELD, T. On crafting a fisheries co-management arrangement in the estuary of Patos Lagoon (Brazil): opportunities and challenges faced through implementation. Marine Policy, v. 28, n. 6, p. 503-522, 2004.

; VASCONCELLOS, M. Fishers knowledge role in the management of artisanal fisheries in the estuary of Patos Lagoon, southern Brazil. In: NEISS, B.; HAGGAN, N. (Eds.). Putting fishers' knowledge to work. Oxford: Blackwell, 2005.
; LAVKULICH, L. Fitting institutions to ecosystems: the case of artisanal fisheries management in the estuary of Patos Lagoon. Marine Policy, v. 26, n. 3, p. 179-196, 2002.

KRAUSE, G.; GLASER, M. Social Equity in the Coastal Zone: Coastal Dynamics, Socio-Economic Structure and Legislation in the Bragança Region (Pará, North Brazil). In: "RIGHTS AND DUTIES IN THE COASTAL ZONE" MULTIDISCIPLINARY SCIENTIFIC CONFERENCE ON SUSTAINABLE COASTAL ZONE MANAGEMENT. Stockholm, Sweden. Anais. Disponível em: <http://www.beijer.kva.se/conference2003/Krause_Glaser.pdf $>$. Acesso em: jan. 2006.

LIMA, L. G. Aspectos do conhecimento etnoictiológico de pescadores citadinos profissionais e ribeirinhos na pesca comercial do Amazonas Central. Dissertação (Mestrado) Universidade Federal do Amazonas. 99p. Manaus, AM, 2003.

LIMA, J. H. M.; NETO, J. D. O ordenamento da pesca marítima no Brasil. Boletim Técnico-Científico CEPENE, v. 10, n. 1, 2002.

LORENZEN, K.; ALMEIDA, O. T.; AZEVEDO, C. Bio-economic analysis of fisheries management policies for the lower Amazon. Ocean and Shoreline Management (Submetido), 28 p., 2005.

MATEUS, L. A. F.; CATELLA, A. C.; PENHA, J. M. F. Considerações sobre o manejo da pesca no estado de MT. Embrapa Pantanal: ADM - Artigo de Divulgação na Mídia, 1-3. 2002.

McGRATH, D. G.; ALMEIDA, O. T.; CROSSA, M.; CARDOSO, A.; CUNHA, M. Working towards community-based ecosystem management of the Lower Amazon floodplain. PLEC News and Views n. 6, p. 3-10, 2005. Disponível em: $<\mathrm{http}$ ://www.whrc.org/resources /published_literature/pdf/ McGrathetalPLEC.05.pdf>. Acesso em: fev. 2006.

; CARDOSO, A.; SÁ, E. P. Community Fisheries and Co-Management on the Lower Amazon Floodplain of Brazil. In: INTERNATIONAL SYMPOSIUM ON THE MANAGEMENT OF LARGE RIVERS FOR FISHERIES, 2., 2004. Proceedings. Volume II. WELCOMME, R.; PETR, T. (Eds)., FAO Regional Office for Asia and the Pacific. Bangkok, Thailand, RAP, Publication, 17, 2004. Disponível em: $<$ http:// www.mekonginfo.org/mrc_en/doclib.nsf/0/5551587bb5ed2ba 947256fe10021ccd3?OpenDocument $>$. Acesso em: jan. 2006.

; CASTRO, F.; CÂMARA, E.; FUTEMMA, C. Manejo comunitário de lagos de várzea e o desenvolvimento sustentável da pesca na Amazônia. Paper do NAEA, 58, 1996. 
; FUTEMMA, C. Reservas de lago e o manejo comunitário da pesca no Baixo Amazonas: uma avaliação preliminar. Paper do NAEA, 18, 1994.

MONTEIRO, S. M. M.; CALDASSO, L. Análise institucional da pesca artesanal no município de Rio Grande/RS. Mimeo. Centro de Estudos em Economia e Meio Ambiente (CEEMA). Universidade Federal do Rio Grande (FURG), 2004. Disponível em: <http://www2.furg.br/depto/dceac/ceema/ liandraartcadma.pdf $>$. Acesso em: jan. 2006.

MONTENEGRO, S. C. S. A conexão homem/camarão (Macrobrachium carcinus e M. acanthurus) no Baixo São Francisco alagoano: uma abordagem etnoecológica. Tese (Doutorado) - UFSCar. 209p. São Carlos, SP, 2002.

MUÑOZ, J. M. B. The Brazilian National Plan for Coastal Management (PNGC). Coastal Management, v. 29, n. 3, p. 137-156, 2001.

NDM/UFSC. Partial Project Report. Avaliação local participativa de ecossistemas litorâneos no sul do Brasil: Projeto piloto de criação de uma Agenda 21 Local na área da Lagoa de Ibiraquera, municípios de Imbituba e Garopaba, Estado de Santa Catarina, 2004.

OLIVEIRA, R. S. Reserva extrativista marinha: um processo em discussão (comunidade de Porto do Campo-Augusto, Corrêa-Pará). Dissertação (Mestrado) - UFPA. 89p. Belém do Pará, PA, 2003.

OVIEDO, A.; BURSZTYN, M. Challenges for the Co-Management of Fisheries in the Brazilian Amazon. In: WORKSHOP ON WORKSOHP, 3. Bloomington, Indiana University, 2004. Disponível em: <http://www.indiana.edu/ wow3/papers/ wow3_oviedo.pdf $>$. Acesso em: fev. 2006.

PEREIRA, C. Proambiente: programa de desenvolvimento sustentável da produção familiar da Amazônia. Slideshow. World Bank, Debates Ambientais, Brasília, 2003. Disponível em: <http://www.worldbank.org/rfpp/news/debates/debates. htm>. Acesso em: fev. 2006.

PEREIRA, H. Modelos de co-gestão implicam mudanças e adaptações. Revista Jirau (Informativo ProVárzea/Ibama), n. 8, p. 17, 2004a.

PEREIRA, H. S. Iniciativa de co-gestão dos recursos naturais da várzea. Ibama/ProVárzea, Documentos Técnicos, 2, 132 p., 2004b.

PINTO, J.; MOREIRA, T. Manejo comunitário de camarões. Ibama/ProVárzea, Cartilha, 28 p., 2005.
PINTO DA SILVA, P. S. V. Common property to co-management: social change and participation in Brazilians first maritime extractive reserve. Ph.D. Thesis - London School of Economics. 339 p. London, 2002.

From common property to co-management: lessons from Brazil's first maritime extractive reserve. Marine Policy, v. 28 , n. 5, p. 419-428, 2004.

PNUD. Gestão da pesca precisa ouvir pescadores. Experiências de projeto do IBAMA na várzea amazônica mostram que a imposição de regras aos ribeirinhos não funciona e gera conflitos. Notícia PNUD. 2006. Disponível em: $<$ http://www.pnud.org.br/meio_ambiente/reportagens/index. php?id01=1643\&lay=mam\#>. A

PROVÁRZEA/IBAMA. Manejo de Pesca se consolida pela ação comunitária. Revista Jirau (Informativo ProVárzea/ Ibama), v. 6, p. 13-14, 2004.

QUEIROZ, H. L. A reserva de desenvolvimento sustentável Mamirauá. Estudos Avançados, v. 19, n. 54, p. 183-203, 2005.

REBELO, G. H. Quelônios, jacarés e ribeirinhos no Parque Nacional do Jaú (AM). Tese (Doutorado) - UNICAMP. 156p. Campinas, SP, 2002.

REIS, E. G; D'INCAO, F. The present status of artisanal fisheries of extreme Southern Brazil: an effort towards communitybased management. Ocean \& Coastal Management, v. 43, n. 7, p. 585-595, 2000.

RODRIGUES, A. M. T.; BRANCO, E. J.; SACCARDO, S. A.; BLANKENSTEYN, A. A exploração do caranguejo Ucides cordatus (Decapoda:Ocypodidae) e o processo de gestão participativa para normatização da atividade na região sudeste-sul do Brasil. Boletim do Instituto de Pesca, v. 26, n. 1, p. 63-78, 2000.

RUFFINO, M. L. Strategies for Managing Biodiversity in Amazonian Fisheries. In: Blue Millennium: Managing Global Fisheries for Biodiversity. UNEP/BPSP. Mimeo. 2001. Disponível em: $<$ http://www.unep.org/bpsp/Fisheries/Fisheries\%20 Case\%20Studies/ RUFFINO.pdf $>$. Acesso em: jan. 2006.

Participatory management of fisheries in the Brazilian Amazon. In: INTERNATIONAL SYMPOSIUM ON THE MANAGEMENT OF LARGE RIVERS FOR FISHERIES, SUSTAINING LIVELIHOODS AND BIODIVERSITY IN THE NEW MILLENNIUM, 2. Phnom Penh, Kingdom of Cambodia. Book of Abstracts. Phnom Penh, MekongRiver Commission. 2003a. Disponível em: <http://www.lars2.org/>. Acesso em: jan. 2006. 
. Provárzea - a natural resource management project for the Amazon floodplains. INTERNATIONAL SYMPOSIUM ON THE MANAGEMENT OF LARGE RIVERS, 2. Phnom Penh, MekongRiver Commission, 2003b. Book of Abstracts. Disponível em: <http://www.lars2.org/>. Acesso em: jan. 2006.

. (Coord.) A pesca e os recursos pesqueiros na Amazônia brasileira. Manaus: Ibama/ProVárzea, 272 p., 2004.

SEIXAS, C. S. State-property, Communal-property or Openaccess? The Case of Ibiraquera Lagoon, Brazil. In: BIENNIAL CONFERENCE OF THE INTERNATIONAL ASSOCIATION FOR THE STUDY OF COMMON PROPERTY (IASCP), 9. Bloomington, USA, 2000. Proceedings Disponível em: $<$ http:// dlc.dlib.indiana.edu/archive/00001028/00/ seixasc041100. pdf $>$. Acesso em: jan. 2006.

Barriers to local-level, participatory ecosystem assessment and management in Brazil. In: MILLENNIUM ECOSYSTEM ASSESSMENT CONFERENCE "BRIDGING SCALES AND EPISTEMOLOGIES: LINKING LOCAL KNOWLEDGE AND GLOBAL SCIENCE IN MULTISCALE ASSESSMENTS". Alexandria, March, 2004. Proceeding MEA Conference. Disponivel em: $<\mathrm{http}: / /$ ma.caudillweb. $\mathrm{com} /$ documents/bridging/papers/ seixas.cristiana.pdf>. Acesso em: jan. 2006.

SEIXAS, C.; TROUTT, E. Socio-economic and ecological feedbacks in lagoon fisheries: management principles for a co-evolutionary setting. Interciencia, v. 29, p. 362-368, 2004.

SILVA, M. R.. Povos de terra éágua: a comunidade pesqueira Cantos do Mangue, Canguaretama (RN) - Brasil. Dissertação (Mestrado) - Universidade de São Paulo (USP). 126p. São Paulo, SP, 2004.

SILVA-FORSBERG, M. C. Manejo da pesca dos grandes bagres migradores: desafios e possibilidades. Revista Jirau (Informativo ProVárzea/Ibama), n. 5, p. 4-5, 2004.

SILVA JÚNIOR, U. L. Gestão participativa fortalece monitoramento e controle. Revista Jirau (Informativo ProVárzea/ Ibama), n. 7, p. 14-15, 2004.
SIMONIAN, L. T. L.; GLASER, M. Extractive reserves and the question of sustainability: recent experiences in north of Brazil. In: GERMAN-BRAZILIAN WORKSHOP ON NEOTROPICAL ECOSYSTEMS - ACHIEVEMENTS AND PROSPECTS OF COOPERATIVE RESEARCH, Hamburg, 2000. Proceedings. Disponível em: <http://www.biologie. uni-amburg.de/bzf/oknu/proceedingsneotropecosys/p0767_simonian.pdf $>$. Acesso em: jan. 2006.

SOUZA, M. R. Etnoconhecimento caiçara e uso de recursos pesqueiros por pescadores artesanais e esportivos no Vale do Ribeira. Dissertação (Mestrado) - Escola Superior de Agricultura Luiz Queiroz. 102p. Piracicaba, 2004.

THÉ, A. P. G. Conhecimento ecológico, regras de uso e manejo local dos recursos naturais na pesca do alto-médio São Francisco, MG. Tese (Doutorado) - UFSCar. 185 p. São Carlos, SP, 2003.

TONI, F. Movimentos Sociais, Governança Ambiental e Desenvolvimento Rural no Brasil. 2004. Relatório. Programa Colaborativo de Investigación "Movimientos Sociales, Gobernanza Ambiental Y Desarrollo Territorial Rural". Disponível em: $<$ http://www.rimisp.cl/getdoc.php?docid=2537>. Acesso em: fev. 2006.

WEIGAND JR., R. The social context of participation: participatory rural appraisal (PRA) and the creation of a marine protected area in Bahia, Brazil. Tese (Doutorado) - University of Florida. 300p. EUA, 2003.

WETZEL, L. B.; POLETTE, M.. ICZM and the Integration of Coastal Management and Protected Area Policies in Brazil. In: THE CHANGING COAST. EUROCOAST/EUCC, Porto,

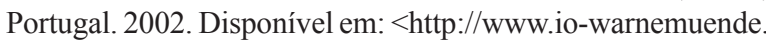
de/homepages/schernewski/Littoral2000/docs/vol3/Littoral2002_12.pdf > . Acesso em: fev. 2006.

WFT/CIDA/UFSCAR - World Fisheries Trust (WFT), Agência Canadense de Desenvolvimento Internacional (CIDA) e Universidade Federal de São Carlos (UFSCar). Projeto Peixes Pessoas e Água. Brasil-Canadá, 2003. Disponível em: $<$ http:// www.worldfish.org/PPA/Projeto.htm>. Acesso em: fev. 2006.

Recebido em outubro de 2008. Aceito em novembro de 2009. Publicado em dezembro de 2009. 